\title{
La perplejidad del sentido
}

\section{Paula Muriel Belmes ${ }^{1}$ \\ Universidad de Buenos Aires Universidad Nacional del Centro de la Provincia de Buenos Aires}

\section{Ensayo}

Material original autorizado para su primera publicación en el Journal de Ciencias Sociales, Revista Académica de la Facultad de Ciencias Sociales de la Universidad de Palermo.

Recepción: 07-04-2019

Aceptación: 07-04-2020

Resumen: En este ensayo nos proponemos revisitar un tema que ha estado presente en la sociología desde sus orígenes: el tema del sentido. Entendemos que una manera de acceso a esta problemática puede ser la reflexión acerca del imperativo cultural que supone que toda sociedad necesita ineludiblemente producir un conjunto de significados validados que actúen como modo hegemónico de sentido y que permita a los sujetos relacionarse entre sí y con el mundo. Ese conjunto de significados, además, presupone la existencia de unos sujetos que, ya por cualidades intrínsecas, ya por posición social, sean los portadores, portavoces, transmisores, productores, reproductores y/o transformadores de esos significados dadores de sentido. Son múltiples las voces que, desde distintos ámbitos, se han pronunciado sobre esta problemática, en especial, en el último tercio del siglo $\mathrm{XX}$ y con mayor énfasis y diversidad en los primeros años del siglo XXI atendiendo a los avances de los grupos y movimientos en el reclamo del reconocimiento de la ruptura de las formas identitarias binarias. Sin embargo, nos enfocaremos en una propuesta en particular, la del sociólogo Daniel Bell quien nos desafía a movernos hacia otros puntos de vista al sugerir que el sentido se va fragmentando en esferas autónomas y esa autonomía podría ser la fuente de la perplejidad.

Palabras clave: sociología; modernidad; sentido; sociedad.

\section{Perplexity over Sense}

Abstract: The aim of this essay is to revisit a topic that has been present in sociology since its origins: the problematic about social sense. We understand that a way of accessing this

\footnotetext{
${ }^{1}$ Socióloga por la Universidad de Buenos Aires (UBA). Docente universitaria. Correo electrónico: murielbelmes@gmail.com
} 
problem may be the reflection on the cultural imperative that assumes that society must unavoidably produce a set of validated meanings that act as a hegemonic mode of social sense and that allow subjects to interact with each other and the world. This set of meanings, in addition, presupposes the existence of individuals who, due to intrinsic qualities, and/or their social position, become the bearers, spokesmen, transmitters, producers, reproducers and / or transformers of those meanings. So many voices have been heard on this issue but we will focus in one in particular, the one by Daniel Bell who challenges us to move towards other points of view by suggesting that meaning is fragmented in autonomous spheres and that autonomy could be the source of perplexity.

Keywords: sociology; modernity; sense; society.

\section{Introducción}

Para el hombre educado la muerte no tiene sentido (Tolstoi). Y no lo tiene porque la vida individual civilizada, situada dentro de un progreso indefinido, no puede, según su sentido inmanente, llegar a un límite determinado... Y puesto que la muerte carece de sentido, tampoco lo tiene la cultura como tal, que precisamente por su continua "progresividad" despoja a la muerte de sentido (Weber, 1969, p. 114)

Hay un aspecto que nos atraviesa como hilo invisible desde la instauración de la historicidad lineal en Occidente hasta nuestros días: la perplejidad frente a la posibilidad del fin del sentido. Esta perplejidad no ha sido ajena al pensamiento social que ha intentado resolverla de diversos modos. En este ensayo entendemos que una manera de acceso a esta problemática puede ser la reflexión acerca del imperativo cultural que supone que toda sociedad necesita ineludiblemente producir un conjunto de significados validados que actúen como modo hegemónico de sentido y que permita a los sujetos relacionarse entre sí y con el mundo. Ese conjunto de significados, además, presupone la existencia de unos sujetos que, ya por cualidades intrínsecas, ya por posición social, sean los portadores, portavoces, transmisores, productores, reproductores y/o transformadores de esos significados dadores de sentido.

La idea de lo sacerdotal- en el sentido de sujetos que ocupan posiciones de privilegio fundadas en su relación con lo desconocido y que otorgan sentido desde esa posición acecha a la reflexión sociológica desde sus inicios. ¿Cómo reemplazar a la fuente de sentido hegemónica cuando su fundamento ultramundano sucumbe ante el avance de una racionalidad que no reconoce más tradición que la humanidad misma? Los ejercicios reflexivos, los trabajos explicativos y las propuestas transformadoras de todo signo, se hicieron cargo tempranamente de la necesidad de controlar a la dimensión ideativa de nuestra cosmovisión organizándola en un sentido legible y cristalino. Los intelectuales -la 
intelligentsia-, los filósofos; todos recortes de segmentos sociales que intentaron desde su posición terrenal reivindicar la valía de ser servidores de lo absoluto (Debray, 1995).

Son múltiples las voces que desde distintos ámbitos, se han pronunciado en aquella dirección, por ejemplo, los debates de fines del siglo XX que organizados bajo la forma de una rebelión posmoderna desfragmentaron a la modernidad y la cuestionaron en sus fallos más ostensibles: las promesas incumplidas de armonía y felicidad. Sin embargo, las reflexiones sobre sentidos alcanzados o inalcanzables caracterizaron a todo el siglo que nos precedió. Un comienzo prometedor que miró a la Revolución Rusa como un faro productor de nuevas sociedades, un período de entreguerras que anunció el fin de la utopía y la emergencia del horror $y$, finalmente, el estado de bienestar que en su guerra fría se perfiló triunfante sobre las promesas de la modernidad y se adaptó cómodamente a las interrogaciones de la posmodernidad.

En los años 1950 y 1960, la sociología se desplegó de forma exponencial, en especial alrededor de los interrogantes que traía un mundo dividido en bloques ideológicos y en espacios de desarrollo que trajeron un hiperdesarrollo del mercado y del consumo. Estos nuevos territorios y confines provocaron una necesidad social de sentido que pudiera pensar la diversidad y la fragmentación como partes armonizables hacia múltiples territorios. El desafío entonces para una ciencia con menos de un siglo fue enorme: dar respuestas a preguntas que cambiaban permanentemente. En esta tarea se manifestaron variadas tendencias - funcionalismo, postestructuralismo, interaccionismo simbólico, estudios culturales y otras- Entre estas, la intención de actualizar a los clásicos (Marx, Durkheim y Weber) con una mirada de fines de siglo tal como se presenta en algunas de las tesis de Daniel Bell, nos produce curiosidad. Este autor, a comienzos de la década de 1960, ¿publicó un texto llamado The end of Ideology? en el que se anticipan algunos de los debates que cobrarán fuerza hacia fines de 1980 y durante la década siguiente y que en su propia obra se continua con El advenimiento de la sociedad post-industrial (1976) y Las contradicciones culturales del capitalismo (1977). Por lo tanto, en los próximos apartados nos ocuparemos de describir y analizar los modos en los que el problema del sentido se va fragmentando en esferas autónomas, según la perspectiva de Bell, y como para la modernidad esta emergencia de un sentido social con rupturas genera perplejidad.

\section{El mundo según Bell}

Una sociedad, tres esferas, es la síntesis del análisis de lo social para Daniel Bell, un analista con extensa trayectoria en el campo de las tesis osadas y los advenimientos probables. Ya en 1973, cuando los ecos del mayo francés todavía se escuchaban y, en su Norteamérica, los jóvenes (entre otros sectores sociales) llenaban las calles de las ciudades 
protestando contra la guerra de Vietnam, publicaba una obra titulada: El advenimiento de la sociedad post-industrial que se completaría con Las contradicciones culturales del capitalismo ambas unidas por el análisis de tendencias estructurales que devienen predictivas respecto del futuro de Occidente. Será en ese contexto donde él recupera una problemática muy próxima a las primeras reflexiones sociológicas y que, según sus propias palabras, puede sintetizarse en la siguiente frase "Toda sociedad trata de establecer un conjunto de significados mediante los cuales las personas pueden relacionarse con el mundo [...] Esos significados están encarnados en la religión, la cultura, y el trabajo" (Bell, 1996, p.143). Cuando se producen desplazamientos, rupturas o pérdidas en este conjunto de significados que cuestionan la validez del grupo en su totalidad, se avecina una suerte de estado de angustia generalizada en el que frenéticamente las personas salen a buscar nuevas significaciones. Frente al nihilismo escapista de la modernidad tardía, este sociólogo se pregunta: “¿Qué nos mantiene aferrados a la realidad, si nuestro sistema secular de significados resulta ser una ilusión? Me arriesgaré a dar una respuesta anticuada: el retorno de la sociedad occidental a alguna concepción de la religión" (Idem, p.40).

En las sociedades modernas, emergentes de la secularización de la transición del feudalismo al capitalismo, se produjo un fenómeno de sustitución de la religión por la utopía; una utopía subordinada a la ideología que no se realizaría en un ideal trascendente sino como tendencia ineludible de la historia, según el crecimiento de la racionalidad, la técnica y la ciencia. Pero esta tendencia mostró rápidamente su carácter ilusorio y, por lo tanto, en nuestra realidad, el problema podría formularse como una suspensión de la creencia, que queda en estado de quietud hasta que en el horizonte se perfile una creencia sustitutiva. Ahora bien, ¿quién está en condiciones de reponer esos significados? Esta pregunta nos permite interrogar a esta propuesta sobre el lugar de los intelectuales en la sociedad contemporánea. Adelantando un poco el final de este ensayo, decimos que Bell, aunque comparte el pesimismo weberiano sobre la capacidad de la ciencia para dar esos significados; cree que, en una nueva política de carácter comunal, inspirada en los tradicionales valores de la polis, podrá proveer de sentidos unificadores liberados de toda pretensión universalizante pero con capacidad de establecer los significados necesarios para vivir en el mundo social.

Para comprender cómo Bell alcanza este diagnóstico es necesario describir, sumariamente, algunos de los ejes centrales de su análisis de la sociedad post-industrial, el que se encuentra enfocado en los fenómenos que se sucedieron en la sociedad norteamericana. En este nuevo escenario, señala el sociólogo mirando las transformaciones del último tercio del siglo XX, las tecnologías -en su sentido clásico pero que también incluye a la tecnología intelectual- y el conocimiento teórico aparecen como los principios para las innovaciones y las políticas. Esas innovaciones modelan todos los órdenes de la sociedad y, 
por lo tanto, a la sociedad misma en su estructura. Pero dado que el camino del despliegue técnico no se acompaña de dispositivos eficientes de organización del sentido social, en el capitalismo actual, el hedonismo se convirtió en el valor predominante produciendo una separación entre la cultura, la economía y la política. Esta separación de órdenes, sin embargo, fue y es una realidad inteligible en la historia que determina temporalidades diversas y ejes que estructuran la vida de los hombres de manera diferenciada. En este punto no debemos olvidar que Bell se nutre de las tradiciones sociológicas clásicas y las combina de manera ecléctica, según se ubique en cada uno de los órdenes analizados.

Decíamos al comienzo que "una sociedad, tres esferas" podría resumir a esta propuesta sociológica pero no son sólo tres esferas -los órdenes tecnoeconómico, político y cultural- sino también tres sociedades históricas con características diferenciadas: la sociedad preindustrial, la industrial y la post-industrial que son leídas desde esas tres esferas. En esos modos sociales los individuos se vinculan, y explican esa vinculación -establecen significados sociales-, con el mundo real a través de tres maneras: la religión, el trabajo y la cultura. Sin embargo, aunque cada uno de ellos presenta cierta primacía según la sociedad de la que se hable, Bell apela a una definición un poco simple en su enunciación (aunque parece parafrasear la tradicional definición materialista del ser) para dar cuenta de las transformaciones que se producen en cada formación histórica; según sus propias palabras: "buena parte del carácter de los hombres y del patrón de sus relaciones sociales está modelada por el género de labor que hacen" (Bell, 1996, p. 143)

El primero de los órdenes, el tecno-económico, es el ámbito de la producción y de la asignación de bienes y servicios que ordena la estructura social. El segundo es el orden político cuya función es garantizar (a través del uso legítimo de la violencia y la regulación de los conflictos) los parámetros de lo justo en una sociedad. El último orden es el cultural que involucra al ámbito de las formas simbólicas, especialmente el simbolismo expresivo, como espacio de exploración y expresión de los sentidos de la existencia humana.

Estos tres órdenes permanecían unidos por la religión -en la sociedad preindustrialo por el trabajo -en la sociedad industrial-; pero en la sociedad post-industrial, por el propio carácter de la cultura modernista, se produjo un estallido del sentido que debilitó los lazos sociales y que será necesario reconstruir bajo alguna forma de religiosidad contenida en agrupaciones comunitarias. El sentido de lo religioso aparece más como la necesidad intrínseca de la sociedad de distinguir entre lo sagrado y lo profano, al estilo Durkheim, que como un discurso sobre lo divino (Durkheim, 1992). Lo religioso sería el lugar de la distinción identitaria entre un adentro y un afuera en una metáfora espacial que define por posición y no por valor, los sentidos de pertenencia (Debray, 1996). 
El cambio de una sociedad a otra se explica por las transformaciones en el orden tecno-económico, transformaciones que comportan -volvemos a las más puras tradiciones sociológicas- cambios en la conciencia. Según esta perspectiva existencialista "el hombre es "arrojado" al mundo, debiendo enfrentarse con poderes extraños y hostiles que trata de comprender y dominar" (Bell, 1996, p. 145); en cada mundo el sujeto jugará un juego diferente. Veamos un poco como son estos juegos y como aparecen estas relaciones en cada una de las sociedades. En las sociedades preindustriales la vida es un juego contra la naturaleza que es hostil y desconocida. El mundo está dominado por las fuerzas naturales y la vida de los individuos se ajusta al ritmo de las estaciones y las condiciones meteorológicas. Como dice nuestro autor el mundo es un mundo encontrado y los primeros discursos sobre el significado de ese mundo son discursos religiosos que se ocupan de distinguir entre lo sagrado divino y lo profano humano, entre lo regular y lo excepcional, entre lo inexplicable y lo conocido. Son sociedades que aparecen unidas por un fuerte lazo social sostenido por la ausencia de lo individual. Este lazo se mantiene anudado por solidaridad mecánica y la conciencia colectiva está modelada por esa distinción religiosa. El orden de la producción se somete a esta cosmología regida por una naturaleza cuyas leyes parecen ser las del capricho o el azar.

En las sociedades industriales el juego cambia, la naturaleza ya no es el enemigo; ahora se juega contra la naturaleza fabricada. Ya no es un mundo regido por el azar. Es un mundo técnico y racionalizado, regido por el tiempo de la máquina y el reloj, por la programación y la administración. En su labor, el hombre hace cosas y su producción transforma al mundo en un universo de cosas; cosas que se le vuelven extrañas y que parecen tener existencia propia - estas referencias a los conceptos de alienación en Hegel y de fetichismo de la mercancía en Marx se presuponen como dadas-. El desarrollo tecnológico y, más importante aún, el triunfo de la concepción newtoniana de ciencia, que abrió la posibilidad de descubrir y enunciar las leyes que rigen el desarrollo natural, permitieron construir un universo de significaciones sustentadas en la confianza infinita en la capacidad del hombre de dominar a la naturaleza.

El lazo social mutó y la cosmovisión religiosa con sentido de sacralidad divina se resquebrajó en favor de una perspectiva tan idealista como aquella, pero ahora secularizada y sometida a la suprema Razón. El problema en este mundo técnico es que el individuo se retrae hacia una idea de yo verdadero que se distancia de los diversos roles que ocupa en la red social. La interdependencia basada en la desemejanza y articulación de funciones fortalece esta dualidad. Esta misma idea de yo verdadero juega un rol central en la concepción freudiana de individuo y aporta a una concepción del yo en conflicto con lo social y lo natural. El individuo moderno domestica a la naturaleza al precio de eliminar los rastros 
de lo natural de su propia constitución individual-social. El mundo de las cosas acosa al mundo de los sentidos.

Las sociedades post-industriales ya no se ocupan de la naturaleza. El juego ahora es entre personas. La cooperación y la reciprocidad, antes ajustadas a la programación científica de la producción, se producen en otro escenario: el de la educación. El mundo es puro mundo social ya que, la esfera tecno-económica se autonomiza y la organización comunitaria opera como base las decisiones políticas. El mercado como lugar de intercambio (más que como organizador de diferencias) ya no manda en la vida de los individuos y la cultura sigue su propio curso sin ocuparse de proveer sentidos unificados que mitiguen la angustia, especialmente, la de la finitud. El optimismo iluminista ya está enterrado y ahora el mundo se diluye en esferas autónomas que operan bajo sus propias lógicas. El problema es que, al eliminar al otro exterior, que indistintamente apareció como enemigo a doblegar o como fuerza superior a acatar, los humanos nos vemos obligados a mirarnos a nosotros mismos y, a partir de allí, construir un lazo fundado en una conciencia común; frente a esto el autor se pregunta "¿con qué reglas y con qué concepciones morales? [..] (ya que) sin la naturaleza o la tekhné ¿qué puede unir a los hombres?" (Bell, 1996, p. 146). Si el mundo preindustrial se unificó bajo la religión y el mundo industrial bajo la razón y el progreso, el mundo postindustrial debería hacerlo en la cultura, pero este mundo social sólo puede ser caracterizado como viviendo en el temor.

Estos juegos sociales requirieron, históricamente, de un suministro de sentido que fue provisto, como ya dijimos, por la religión, el trabajo y la cultura. El análisis de la provisión de sentido, se basa en Bell, en la tradicional distinción entre lo sagrado y lo profano que supone un mundo que se encuentra dividido en dos clases de objetos y símbolos: los sagrados y los profanos. Estos dos grupos están separados y opuestos. La característica principal de lo sagrado reside en que, en su delimitación, se establecen un conjunto de rituales, normas y prohibiciones que permiten distinguir ese espacio de su opuesto profano. $Y$ aunque esta sacralidad no deba corresponder necesariamente a algo divino, sobrenatural o mágico -modo tradicional de expresión de la conciencia en la religión- la debilidad del lazo social, en su ausencia, parecería demostrar que la restitución de cierta sacralidad sería el camino para recomponer el mundo social.

Si en toda sociedad la unidad se genera por la aceptación compartida de un orden moral, la religión fue el modo de conciencia del orden social compartido más extendido y duradero. Este modo tradicional del lazo sufre su primera gran transformación en Occidente con la Reforma protestante. Weber (1985) ya ha demostrado como la nueva concepción del trabajo profesional con su sacralización en Lutero y como medio ascético por excelencia en Calvino, Baxter, Wesley y otros reformadores, genera un nuevo resquebrajamiento en el 
mundo mágico y en la relación de los hombres con su dios. Ahora el trabajo será el centro de la vida en la fe y la religión se irá retrayendo cada vez más hacia el ámbito de lo privado y lo personal. El contenido vocacional del trabajo se perderá rápidamente y la secularización absoluta de esa actividad marcará el inicio del nuevo mundo: el técnico y racional.

No sólo el contenido vocacional del ejercicio profesional quebró la unidad del mundo preindustrial. También la recuperación de temáticas presentes en la cosmovisión cristiana ayudó a su propia retracción. Si el mundo había sido hasta ese momento un texto escrito por dios a descifrar por los hombres, ese desciframiento implicó la postulación de una filosofía de la historia que abandonó la circularidad presente en las concepciones de la antigüedad pagana y que pensaba el transcurrir del tiempo como una sucesión de etapas progresando desde la creación hacia el fin de la historia (el reencuentro con el paraíso perdido). El mundo técnico cambió al autor de ese devenir, pero no renegó de esa filosofía. Hegel, un representante destacado de esta transformación, decía que la historia es el proceso inmanente a través del cual la conciencia individual va recorriendo el camino que la aproxima al saber absoluto. Este camino, que va del yo al nosotros, lo recorre bajo la presencia permanente del Espíritu absoluto que representa ese nosotros en tanto absoluto y, por esa misma condición, resuelve el problema del enfrentamiento del yo con la realidad en términos gnoseológicos alcanzado ese momento se llegaría al fin de la historia. Un lector rebelde de Hegel será quien naturalice ese proceso y lo remita a las estructuras materiales poniendo al hombre, al ser humano concreto, viviente, en el centro de la argumentación. Marx vio en el creciente dominio del hombre sobre la naturaleza un primer modo de progreso en la historia. El segundo, que no es sucesivo sino paralelo, implicaría la recuperación de la libertad humana hoy sujeta a las cadenas de la dominación, dominación expresada fundamentalmente en las relaciones de propiedad y en la alienación. El trabajo aparecerá en su obra como medio central para la definición de esa humanidad y ya conocemos lo que les pasa a los individuos en el mundo industrial fetichizado por la mercancía. En palabras de Bell, en el mundo técnico el trabajo marca la pauta de las relaciones y "la historia como un demiurgo filosófico, era el agente por el cual los hombres pasarían del reino de la necesidad al reino de libertad" (Bell, 1996, pp. 146-147).

Cuando en la sociedad post-industrial la cultura reemplaza al trabajo y a la religión como modos de vinculación y como medio de autorrealización, se termina de desmoronar el mundo cerrado del sentido. Para el sociólogo norteamericano, la cultura modernista nunca podía ocupar ese lugar privilegiado de dadora de sentido ya que, en lugar de ocuparse de definir los dioses y los demonios, lo sagrado y lo profano, se dedicó a exponer y explorar esas definiciones.

El cambio de que hablo -que no está localizado en ninguna persona particular o punto específico en el tiempo, sino que es un fenómeno cultural general- se 
produjo con la quiebra de la autoridad teológica de la religión a mediados del siglo XIX. La cultura, particularmente la corriente emergente que ahora llamamos modernismo- asumió, en efecto, la relación con lo demoníaco. Pero en lugar de domesticarlo, como trató de hacer la religión, la cultura modernista comenzó a aceptar lo demoníaco, a explorarlo, a regodearse en él y a contemplarlo (correctamente) como la fuente de cierto género de creatividad (Bell, 1996, p. 153).

Entonces, en esta sociedad, el proclamado fin de la historia devino fin de la ideología y en lugar de inaugurar el reino de la libertad, trajo angustia por la desaparición de la utopía como espacio virtual de recuperación del paraíso perdido.

\section{El fin de la ideología}

La proposición más provocativa que Daniel Bell enunció fue la del fin de la ideología. Esta tesis es el corolario de un análisis de la intelectualidad norteamericana en las décadas que van de 1930 a 1950 y parece una expresión de la desilusión del propio autor respecto de la posibilidad de alcanzar y realizar un cierto tipo de utopía. El propio Bell es un representante de la generación de intelectuales que en los años de 1930 eran adolescentes y militantes de diversas agrupaciones de izquierda. Su paso por la Young People's Socialist League así lo testimonia. Pero las esperanzas utópicas de estos jóvenes se desvanecieron con la guerra, se transformaron en escépticos e imprimieron ese escepticismo a las nuevas generaciones. Según la descripción que él hace de esta situación, la inhabilidad para definir a un enemigo (base de toda operación identitaria primaria y, según algunas teorías, de toda política) hace que se pierda el sentido heroico de la vida y de la actividad intelectual y, junto con ello, se pierde también la sensación de participar en la definición de los sentidos sociales.

Si en los años de 1920 las vanguardias vieron en el gusto burgués el enemigo a combatir y en la década siguiente la lucha se politizó y el capitalismo en general, su forma fascista en particular y, por el otro lado el stalinismo, devinieron los monstruos a matar; en la década de 1940 el universo cambió y las viejas certezas se tornaron en imágenes del horror imposibles de contestar. Según Bell, el principal fenómeno de la política en ese período fue el de la despersonalización, es decir "la denigración del individuo a través de la impersonalidad de la matanza" (Bell, 1960, p. 294) la transformación del arte de la guerra en un plan burocrático de eliminación sistemática tecnologizada de los individuos-enemigos. Fue la culminación del proceso de mecanización de la sociedad, "la sociedad moderna, siguiendo a Hannah Arendt, devino un aparato burocratizado destinado a suprimir o evocar esa violencia intrínseca de manera periódica" (Bell, 1960, p. 294). Luego de esta experiencia en el límite, los intelectuales norteamericanos de izquierda se convirtieron a una nueva religión: la anti-ideología, en la que el racionalismo se transformó en una mala palabra. Abandonada 
la utopía, el intelectual se arrellanó cómodamente en su sillón académico aceptando "el estado de bienestar y aprobando la existencia de un enemigo, la Unión Soviética, de modo acrítico" (Bell,1960, p. 294), olvidando las viejas disputas y viviendo en una sociedad que legitimó una posición hegemónica de rechazo a cualquier visión con tinte utópico y/o ideológico.

La década de 1950 marca una cesura en el pensamiento occidental, especialmente en Norteamérica. El fin de la ideología se transformó por mímesis en fin de la utopía y esta es la trampa. Como ya presentáramos al comienzo de este ensayo, para Bell la subsunción de la utopía en la ideología es la razón del derrumbe conjunto de ambas propuestas como proveedoras de sentido. Pero como no ha desaparecido la necesidad de producir ciertas prefiguraciones sobre el mundo, el nuevo juego consistiría en encontrar un programa utópico, liberado de ideología, que responda a las preguntas de "hacia dónde ir, como llegar, cuánto cuesta llegar allí y quien va a pagar el viaje" (1960, p. 294). El fin de la ideología representaría, por lo tanto, el fin de la fórmula fácil para el cambio social. La pregunta aquí es ¿quién decidirá las respuestas a esas preguntas? Para responderla, Bell analizará a los políticos y los tecnócratas en la sociedad post-industrial.

\section{Los nuevos profetas}

Daniel Bell adhiere a la idea que toda sociedad trata de establecer un conjunto de significados a través de los cuales las personas pueden relacionarse con los mundos y, en esta línea, podríamos decir que se inscribe en las tradiciones que presentan una continuidad entre la función sacerdotal e intelectual. Sin embargo, esta continuidad vale para los mundos preindustrial e industrial pero cuando se trata del mundo post-industrial la situación es distinta.

El pasaje del primer mundo al segundo fue traumático, pero supuso continuidad. La razón divina se tornó en razón a secas y su reinado dominó a la nueva estrella del sentido: la ciencia. La racionalidad, su desenvolvimiento en, y a través de, la historia, fue el corazón de la teoría sociológica. Marx, Durkheim y Weber vieron en el creciente dominio del hombre sobre la naturaleza, en la división del trabajo, en el alargamiento de las cadenas de interdependencia, en la racionalización de la economía, la técnica, la contabilidad y las leyes, el triunfo de la razón sobre la magia, pero también, dada la sutileza de sus pensamientos, pudieron ver los dobleces que este desarrollo comportó. El mundo industrial, entonces, ya no necesitaba de sacerdotes que definieran lo sagrado y lo profano. Ahora se requería de técnicos, capaces de interpretar y dirigir el proceso productivo. En la transición a la sociedad post-industrial la función de provisión de sentido se encuentra vacante no porque no sea necesaria (rasgo de continuidad) sino porque quienes ocupan los lugares del estrato intelectual y tecnocrático al desistir de la dimensión prefiguradora que tenía su rol hasta 
mediados del siglo $\mathrm{XX}$, eligen privilegiar sus propios intereses de manera visible. Antes quienes tenían el saber tenían el poder, ahora, el saber es la fuente de un poder distinto, que se encuentra disperso y que tiene que negociar con quienes ejercen el poder efectivo (el gobierno) que no siempre se rigen por la misma lógica racional que constituye el ethos de la intelectualidad científica y tecnocrática.

El acontecimiento más significativo para la aparición de este nuevo estrato, con vocación de poder, pero limitado en las posibilidades de su ejercicio, es la extensión de la educación. Las nuevas élites fundadas en el saber, nos ilustra Bell, crecen porque el conocimiento es un requisito indispensable para toda actividad en la sociedad contemporánea. La extensión de la educación, entonces: "ha creado un nuevo grupo de comitentes: la intelligentsia técnica y profesional" (Bell, 1994, p.416). El problema con esta nueva élite es que sus integrantes poseen ciertas características comunes, pero no las suficientes para constituir un interés común definido y se diferencian de su antecesora, la élite empresarial, porque el interés económico propio (de casta) no parece guiar su acción colectiva. En la misma línea de este razonamiento, teniendo presente la idea de ruptura, para este sociólogo, lo central es que en la sociedad post-industrial cambió el carácter del conocimiento y aquí se operó la disociación de la que hablamos anteriormente. En este sentido, sostiene que: "se ha vuelto decisivo para la sociedad es el papel central nuevo del conocimiento teórico, la primacía de la teoría sobre el empirismo y la codificación del conocimiento en sistemas abstractos de símbolos que pueden ser trasladados a muchas circunstancias distintas" (Bell, 1994, p. 394). Este criterio tecnocrático, a pesar de reconocer su fuente de universalidad en las tradiciones de la ciencia moderna, se independiza del valor moral de esa universalidad y se rige pura y exclusivamente por la razón técnica, una razón preocupada más por los medios que por los fines y sin pretensión ideativa alguna.

Ahora corresponde preguntar ¿quiénes son? y ¿qué lugar ocupan en la estructura social estos tecnócratas y cómo se relacionan con el poder? Respecto de la primera pregunta, para Bell, la nueva intelligentsia es un conjunto heterogéneo compuesto por cuatro grupos: el científico, el tecnológico, el administrativo y el cultural, y lo único que los une es su defensa común de la idea de aprendizaje. El nudo del cambio en la sociedad post-industrial aparece cuando nos desplazamos de la idea tradicional de estructura social por status a una que mire los situs, es decir, los lugares reales de las actividades. Esta es parte de la respuesta que este sociólogo da a la segunda pregunta. La nueva intelligentsia está en varios sitios, muy diferentes, que expresan intereses diversos y particulares opuestos entre sí. Si antes el status marcaba la adhesión a cierto programa de intereses comunes (la idea de clase social expresa cabalmente esa situación) y en función de esos intereses se hacía o reclamaba cierta política; hoy, para Bell, los situs los constituyen las nuevas unidades de presión y desde ese lugar interpelan al poder político. Lo curioso en esta situación es que, aunque el conocimiento es 
poder, el poder político se ha autonomizado relativamente y puede elevarse por encima de esas disputas recuperando su primacía sobre el mundo técnico. Pero para elevarse en el sentido descripto, el poder político necesitaría cambiar su escala y su visión para alcanzar una altura desde la cual poder representar un interés común, una nueva religión, que reconstruya el lazo social. Así: "la política del futuro no se basará en las disputas entre grupos funcionales de interés económico.... Se ocupará de inculcar una ética social de responsabilidad en nuestro dirigentes, de la demanda de mayor número de comodidades" (Bell, 1996, p. 421). Es decir, tendrá que asumir que el sentido transmitido en la educación y la cultura son tareas del poder. Frente a esta impronta de optimismo "belliano" sólo podemos decir que el futuro, definitivamente, no llegó.

\section{A modo de conclusión}

En este ensayo presentamos la perspectiva sociológica de Daniel Bell como una forma de aproximación a una respuesta posible a la tradicional pregunta de quién provee de sentido a la sociedad y lo que encontramos es que ni las instituciones tradicionales se desprenden de su viejo rol de dadoras de sentido ni la emergencia de estructuras de reemplazo en ese rol han mostrado más que fragilidad al momento de posicionarse en el lugar de garantes y/o productoras de sentidos nuevos. Probablemente el centro de la reflexión está en la redefinición del intelectual.

En Bell aparecen rasgos de definición de los intelectuales que remiten a Karl Mannheim y Alvin Gouldner; pero también, presenta algunas consideraciones que se aproximan a la perspectiva de Claude Lefort. Con relación a los dos primeros, la existencia de un estrato, con intereses propios (con la diferencia que en la propuesta de Bell el estrato es por situs y no por status) y con una función de proveedores privilegiados de sentido, como continuidad respecto de la función sacerdotal; $y$, con Gouldner en particular, las condiciones de posibilidad de aparición de una intelligentsia intelectual y técnica, fundamentalmente, la variable de la educación. Con Lefort comparte la idea de separación de las esferas del saber y del poder en la sociedad post-industrial y la idea que cada esfera tiene reglas de validación propias -aunque el análisis de Lefort es sobre la sociedad moderna en general y en Bell una parte de la modernidad es concebida como la sociedad industrial que presenta continuidad con su antecesora-.

La renuncia al sentido no es una opción en ninguna sociología que herede su fuerza de Marx, Durkheim y Weber y queda claro que, aunque en la sociedad post industrial los sentidos resultan más esquivos que en la época de apogeo de la modernidad, las personas siguen adheridas a las tramas sociales portando y transmitiendo significados que dan sentido a sus vidas. 


\section{Referencias bibliográficas}

Bell, D. (1960). The end of ideology, on the exhaustation of political ideas in the fifties, Illinois: Free Press of Glencoe.

Bell, D. (1994). El advenimiento de la sociedad post-industrial. Madrid: Alianza. [1르 ed. 1976]

Bell, D. (1996). Las contradicciones culturales del capitalismo. Madrid: Alianza. [1 ${ }^{\mathrm{a}}$ ed. 1977]

Debray, R. (1995). El estado seductor. Las revoluciones mediológicas del poder. Buenos Aires: Manantial.

Debray, R. (1996). El arcaísmo posmoderno. Lo religioso en la aldea global. Buenos Aires: Manantial.

Durkheim, E. (1992). Las formas elementales de la vida religiosa. El sistema totémico australiano. Madrid: Akal.

Weber, M. (1969). El político y el científico. Madrid: Alianza Editorial

Weber, M. (1985). La ética protestante y el espíritu del capitalismo. Barcelona: Península. 